\title{
Blood Glucose Regulation during Fasting in Rats under Food Restriction since Birth
}

\author{
Adriana de Souza Vitoriano ${ }^{1}$, Ananda Malta $^{2}$, Helenton Christian Barrena ${ }^{1}$, Maria \\ Montserrat Diaz Pedrosa Furlan ${ }^{3 *}$, Roberto Barbosa Bazotte ${ }^{4}$ and Vilma Godoi Gazola ${ }^{3}$ \\ ${ }^{l}$ Centro de Ciências Biológicas; Universidade Estadual de Maringá, Maringá - PR - Brasil; ${ }^{2}$ Departamento de \\ Educação Física; ${ }^{3}$ Departamento de Ciências Fisiológicas, Universidade Estadual de Maringá, Maringá - PR, \\ Brasil. ${ }^{4}$ Departamento de Farmácia e Farmacologia; Universidade Estadual de Maringá; Av. Colombo 5790, \\ 87020-900, Maringá - PR, Brasil
}

\begin{abstract}
The effect of severe food restriction since birth on regulation of fasting glycemia in male Wistar rats was investigated. The control group (CG) had free supply of chow, while the restriction group (RG) received $50 \%$ of the amount ingested by the CG. The experiments were done in adult (60 days) overnight fasted rats in which glycemia, liver free glucose levels and hepatic glycogen concentration were measured. In part of the experiments in situ liver perfusion was done. The results showed that livers from the $R G$ had higher glycogenolysis rates but lower gluconeogenesis rates from L-alanine $(10 \mathrm{mM})$. Since $R G$ showed maintained glycemia during fasting, it could be concluded that livers from $R G$ produced glucose preferentially from glycogenolysis in detriment of gluconeogenesis. These findings demonstrated that in spite of severe caloric restriction, the metabolic adaptations of the liver did exist to assure the maintenance of blood glucose for brain supply during fasting.
\end{abstract}

Key words: food restriction, rats, liver, gluconeogenesis, glycogenolysis

\section{INTRODUCTION}

Undernutrition in children is characterized by lower physical growth and mental development (De Onis and Blossner, 2003; FAO, 2003; WHO, 2005). However, in rats, undernutrition caused by food restriction since birth has marked effects on body weight development, accompanied by reduction in the muscle mass and fat stores (Mazeti and Furlan, 2008; Vismara and Furlan, 2007).

Several studies have demonstrated changes in the liver metabolism in adult rats submitted to food restriction (Batista et al., 2001; Bazotte et al.,
1989, 2000). These alterations include changes in liver gluconeogenesis, nitrogen removal, and activation of the transaminases (Dhahbi et al., 1999; Hagopian et al., 2003; Spindler, 2001). However, information about metabolic changes in rats submitted to food restriction since birth, particularly about the blood regulation of glycemia during fasting, are scarce. Since L-alanine (L-Ala) is the most important liver glucose precursor in conditions of hypoproteic diet or prolonged fasting (Brosnan et al., 2001), we investigated if severe food restriction since birth could influence the liver metabolism of L-Ala. Moreover, the liver

*Author for correspondence: mmdpfurlan@uem.br 
glycogenolysis and several other metabolic parameters were evaluated.

\section{MATERIALS AND METHODS}

\section{Animals}

Pregnant Wistar rats were housed in individual cages, where they gave birth about a week after their arrival. The newborn litters were reorganized so that each mother had either six (control group, $\mathrm{CG}$ ) or 12 pups (restriction group, RG). Only male animals were used in this investigation. The dams had free access to water and food (Nuvilab CR1®; Nuvital, Curitiba, Brazil) during gestation and lactation.

The pups remained with their mothers until the age of 21 days (weaning), when they were put in groups of four or five in plastic boxes with free access to water. The CG rats also had free supply of chow, while those in the RG group were subjected to a $50 \%$ food restriction (Mazeti and Furlan, 2008; Vismara and Furlan, 2007). No dietary supplementation was given to the RG.

All the experiments were done after overnight fasting when the animals were 45-60 days of age.

The rats were kept under constant light:dark cycles (12 h light:12 h dark) and temperature $\left(22 \pm 2^{\circ} \mathrm{C}\right)$. All the procedures were approved by the Committee of Ethical Conduct in the Use of Animals in Experimentation (CEAE) of the State University of Maringá.

\section{Collection of blood and tissues}

The rats from CG and RG groups were weighted and the blood to measure glycemia was collected from the caudal vein. After that the rats were killed by decapitation and the liver and the retroperitoneal and periepididymal fat pads (left and right) were removed and weighted. The blood collected in heparinized tubes was centrifuged $(3,000 \mathrm{rpm}$ for $5 \mathrm{~min})$ and the plasma was separated to determine glycemia (Bergmeyer and Bernt, 1974).

\section{Calorimetry}

Liver samples were dried in micro-processed stove of forced air circulation (Q-314M; Quimis, Diadema, Brazil) at $60^{\circ} \mathrm{C}$ until constant weight and then grinded to a homogeneous and fine powder. The caloric density of the samples $(\mathrm{kJ} / \mathrm{g}$ dry weight) was determined in a calorimeter bomb (Parr 1261; Parr Instruments Company, Moline,
USA) as previously described by Vismara and Furlan (2007).

\section{Hepatic free glucose and glycogen content}

Livers from $\mathrm{CG}$ and $\mathrm{RG}$ rats were quickly removed, immersed in liquid nitrogen and weighted. About $1.5 \mathrm{~g}$ of the organ was grinded while kept frozen by the addition of liquid nitrogen. Perchloric acid $(0.6 \mathrm{~N})$ was added and the resulting mass was homogenized and centrifuged $(10 \mathrm{~min}$ at $6,000 \mathrm{rpm})$. Aliquots of $100 \mu \mathrm{L}$ of the supernatant were used to determine the levels of free glucose (Bergmeyer and Bernt, 1974).

To another aliquot of supernatant $(100 \mu \mathrm{L})$, amyloglucosidase $(50 \mu \mathrm{L})$ was added along with potassium bicarbonate $(50 \mu \mathrm{L})$ and sodium acetate $(960 \mu \mathrm{L})$. The solution was incubated at $40^{\circ} \mathrm{C}$ in water bath under agitation for two hours, and the enzymatic reaction was interrupted by the addition of perchloric acid $(0.6 \mathrm{~N}, 500 \mu \mathrm{L})$. Finally, after another centrifugation (10 $\mathrm{min}$ at $6,000 \mathrm{rpm})$, the aliquots of supernatant $(100 \mu \mathrm{L})$ were used to determine total glucose concentration, i.e., free glucose plus glycogen-derived glucose (Bergmeyer and Bernt, 1974; Oliveira et al., 2007).

\section{In situ liver perfusion}

The rats were anaesthetized with an intraperitoneal injection of sodium thiopental $(40 \mathrm{mg} / \mathrm{kg} \mathrm{bw})$ and submitted to laparotomy. The livers were perfused in situ using Krebs Henseleit bicarbonate buffer ( $\mathrm{pH}$ 7.4), saturated with $\mathrm{O}_{2} / \mathrm{CO}_{2}(95 / 5 \%)$. The perfusion fluid was pumped through a temperature-controlled $\quad\left(37^{\circ} \mathrm{C}\right)$ membrane oxygenator prior to entering the liver via the portal vein. Samples of the effluent perfusion fluid were collected from the inferior cava vein each $5 \mathrm{~min}$ and the concentrations of glucose, pyruvate (Czok and Lamprecht, 1974), L-lactate (Gutmann and Wahlefeld, 1974) and urea (Gutmann and Bergmeyer, 1974) were measured.

As shown in Figure 1, after a pre-infusion period (15 min without L-Ala), L-Ala $(10 \mathrm{mM})$ was dissolved in the perfusion fluid and infused during $20 \mathrm{~min}$, followed by a post-infusion period (10 min without L-Ala).

The glucose production before the infusion of LAla represented the glucose from glycogenolysis and the difference in the production of glucose during and before the infusion of $\mathrm{L}$-ala represented 
the rate of gluconeogenesis. During the infusion of L-ala, along with glucose, the production of pyruvate, L-lactate and urea was also measured. The differences in the production of glucose, pyruvate, L-lactate and urea during and before the infusion of L-Ala allowed to calculate the area under the curves (AUC), expressed as $\mu \mathrm{mol} / \mathrm{g}$ liver (Table 3).

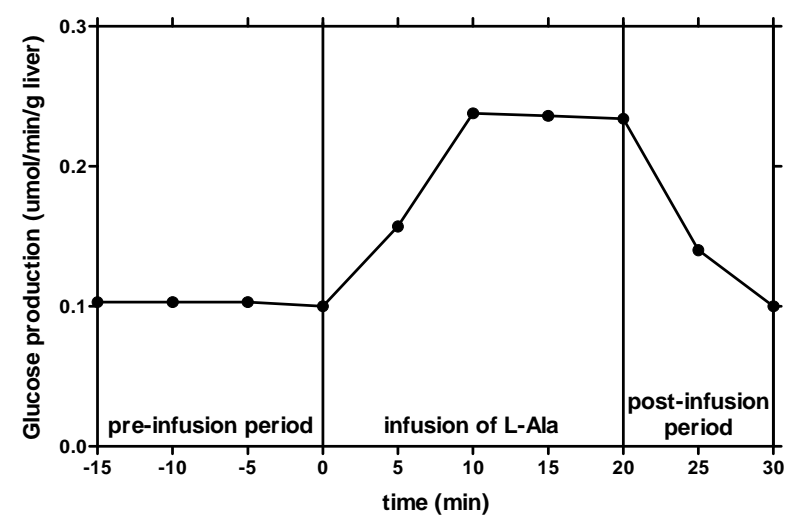

Figure 1 - Demonstrative experiment of a perfusion protocol showing glucose production before (pre-infusion period), during and after (post-infusion period) the infusion of L-alanine $10 \mathrm{mM}$ (L-Ala).

\section{Statistical analysis}

The data were statistically treated using non-paired Student's t test. $\mathrm{P}$ values $<0.05$ were considered significant. The statistical analyses were carried out with Prism v4. The data are shown as means (M) \pm standard deviations (SD).

\section{RESULTS AND DISCUSSION}

Rats from the RG group showed lower $(\mathrm{P}<0.05)$ body weight from lactation until adult age (Table 1). Therefore, when food restriction since birth was given, the body weight gain was lower, as previously described (Aubert et al., 1980; Duff and Snell, 1982; Houdijk et al., 2003). This could be explained by the limited food supply which was not enough to meet the caloric requirement of the RG group (Emery, 2005; Mazeti and Furlan, 2008; Vismara and Furlan, 2007).

The $R G$ showed lower $(\mathrm{P}<0.05)$ relative weights of retroperitoneal and periepididymal fat pads (Table 2). This has been observed when nutrients are available in amounts lower than those needed to secure a normal body growth (Barzilai et al., 1999; Dulloo and Girardier, 1993; Porter et al., 2004; Valle et al., 2005; Waterland and Garza, 1999).

Table 1 - Body weight ( $\mathrm{g}$ ) of rats with free access to food (CG) and rats submitted to food restriction (RG) since birth. $* \mathrm{P}<0.01$ relative to the $\mathrm{CG}$ of the same age; non-paired Student's t test. $\mathrm{n}=$ number of rats.

\begin{tabular}{lcc}
\hline Age & CG $(\mathbf{n}=\mathbf{5 - 8})$ & RG $(\mathbf{n}=\mathbf{5 - 8})$ \\
\hline 5 days & $10.25 \pm 1.17$ & $9.67 \pm 0.82$ \\
20 days & $36.67 \pm 3.78$ & $27.50 \pm 2.03^{*}$ \\
60 days & $245.21 \pm 4.31$ & $131.58 \pm 11.05^{*}$ \\
\hline
\end{tabular}

Table 2 - Relative weight of the liver, retroperitoneal and periepididymal fat pads and caloric density of the liver in the control group $(\mathrm{CG})$ and restriction group $(\mathrm{RG}) . * \mathrm{P}<0.05$ relative to the CG; non-paired Student's $\mathrm{t}$ test. $\mathrm{n}=$ number of animals.

\begin{tabular}{lcc}
\hline & CG $(\mathbf{n}=\mathbf{5 - 8})$ & RG (n=5-8) \\
\hline Liver (g/100 g body weight) & $3.00 \pm 0.22$ & $3.93 \pm 0.46^{*}$ \\
Retroperitoneal fat pads (g/100 g body weight) & $1.14 \pm 0.22$ & $0.24 \pm 0.11^{*}$ \\
Periepididymal fat pads (g/100 g body weight) & $0.99 \pm 0.18$ & $0.51 \pm 0.11^{*}$ \\
Liver caloric density (kJ/g dry weight) & $23.54 \pm 0.11$ & $21.16 \pm 0.51^{*}$ \\
\hline
\end{tabular}


In contrast, the liver weight was higher $(\mathrm{P}<0.01)$ in the RG, indicating that the liver had priority when the nutritional supply was not enough to furnish the metabolic energy for all tissues and organs (Porter et al., 2004).

Calorimetry is a method that provides the amount of total calories from protein, carbohydrate or fat of a dehydrated tissue. The present results showed lower $(\mathrm{P}<0.05)$ caloric density in livers from RG. Since lipids have higher caloric content than protein and carbohydrates, the decreased caloric density in the RG could be the result of a reduction of the lipid content of the liver. Thus, the reduced liver caloric content and the reduced fat pad weight pointed to a general decrease in the total content of body fat.

The total hepatic content of glucose, i.e., free glucose plus glycogen-derived glucose, did not differ $(294.1 \pm 5.45$ and $297.6 \pm 4.95 \mu \mathrm{mol} / \mathrm{g}$ liver in the $\mathrm{CG}$ and $\mathrm{RG}$ groups, respectively), but the content of free glucose was higher $(\mathrm{P}<0.05)$ in the RG than the CG $(5.75 \pm 1.86$ and $3.07 \pm 1.62$ $\mu \mathrm{mol} / \mathrm{g}$ liver, respectively). In agreement, the basal hepatic glucose production, i.e., before L-alanine infusion, was higher $(\mathrm{P}<0.05)$ in the livers from RG.

Considering that the glucose production before LAla infusion resulted from glycogen (Batista et al., 2001), it could be inferred that the livers from RG showed a higher rate of glycogenolysis despite the fact that the hepatic glycogen content was not significantly different between the groups.

In contrast, lower $(\mathrm{P}<0.05)$ liver production of glucose and L-lactate during the infusion of L-Ala was observed. However, the production of urea and pyruvate were similar (Table 3 ).

Table 3 - Glucose production before (pre-infusion period, $10 \mathrm{~min}$ ) and during (20 min) the infusion of L-Ala (10 $\mathrm{mM}$ ) in livers from control $(\mathrm{CG})$ and restriction groups $(\mathrm{RG})$. During the infusion of L-alanine, the liver production of glucose, pyruvate, L-lactate and urea were measured. $* \mathrm{P}<0.05$ relative to the CG; non-paired Student's t test. $\mathrm{n}=$ number of animals.

\begin{tabular}{lcc}
\hline Liver production $(\mu \mathrm{mol} / \mathrm{g}$ liver $)$ & CG $(\mathbf{n = 5 - 8})$ & RG $(\mathbf{n = 5 - 8})$ \\
\hline Glucose & Before L-alanine infusion $($ Basal perfusion) & \\
\hline \multicolumn{4}{c}{} & $0.63 \pm 0.17$ & $3.34 \pm 1.20^{*}$ \\
\hline Glucose & During L-alanine infusion & \\
Pyruvate & $0.83 \pm 0.17$ & $0.45 \pm 0.17 *$ \\
L-Lactate & $1.74 \pm 0.04$ & $2.12 \pm 0.57$ \\
Urea & $1.34 \pm 0.42$ & $2.10 \pm 0.63 *$ \\
\hline
\end{tabular}

Considering that the increased glucose production during L-Ala infusion resulted from gluconeogenesis (Galende et al., 2009), it could be inferred that the livers from RG showed lower rate of gluconeogenesis from L-Ala. In agreement with this result, Liu et al. (1996) showed reduced liver uptake and lower gluconeogenesis from L-Ala in the rats under food restriction. Hagopian et al. (2003) demonstrated that the carbon skeleton of amino acids could be shifted to ketogenesis during food restriction, and in long-term food-restricted rats, ketogenesis is highly favored (Emmanuel and Kennely, 1984; Field, 1989; Westman et al., 2007). Therefore, it was possible that the nitrogen balance in the RG could be funneling L-Ala to other compounds by transamination as a consequence of the reduced protein supply in the diet. In agreement, increased hepatic transaminases and turnover of extra-hepatic proteins during food restriction were reported (Hagopian et al., 2003; Spindler, 2001).

Finally, the main result of this study was the demonstration that food restricted rats since birth showed higher glycogenolysis and lower gluconeogenesis. Thus, considering that gluconeogenesis is a metabolic pathway with high energetic cost, it could be suggested that the preference for glycogenolysis could be an adaptation for glycemia maintenance during fasting to overcome the lower food availability (Batista et al., 2001; Bazotte et al., 2000). In conformity with this suggestion, fasting glycemia did not differ $(\mathrm{P}>0.05)$ between $\mathrm{CG}(97.3 \pm 23.3$ $\mathrm{mg} / \mathrm{dL})$ and $R G$ groups $(103.3 \pm 25.9 \mathrm{mg} / \mathrm{dL})$. 


\section{REFERENCES}

Aubert, R., Suquet, J.P., Lemonnier, D. (1980), Longterm morphological and metabolic effects of early under- and over-nutrition in mice. J. Nutr. 110, 649

Barzilai, N., She, L., Liu, L., Wang, J., Hu, M., Vuguin, P., Rossetti, L. (1999), Decreased visceral adiposity accounts for leptin effect on hepatic but not peripheral insulin action. Am. J. Physiol. 277, E291

Batista, M.R., Curi, R., Lima, F.B., Lopes, G., Bazotte R.B. (2001), Effect of a meal feeding schedule on hepatic glycogen synthesis and gluconeogenesis in rats. J. Biomed. Sci. 8, 256

Bazotte, R.B., Curi, R., Hell, N.S. (1989), Metabolic changes caused by irregular-feeding schedule as compared with meal-feeding. Physiol. Behav. 46, 109

Bazotte, R.B., Batista, M.R., Curi, R. (2000), Mealfeeding scheme: twenty years of research in Brazil. Braz. J. Med. Biol. Res. 33, 985

Bergmeyer, H.U., Bernt, E. (1974), Determination of glucose with glucose-oxidase and peroxidase. InMethods of enzymatic analysis, ed. H. U. Bergmeyer. Academic Press, New York, pp. 1205

Brosnan, J.T., Brosnan, M.E., Yudkoff, M., Nissim, I., Daikhin, Y., Lazarow, A., Horyn, O., Nissim, I. (2001), Alanine metabolism in the perfused rat liver. J. Biol. Chem. 276, 31876

Czok, R., Lamprecht, W. (1974), Pyruvate, phosphoenolpyruvate and D-glycerate-2-phosphate. In-Methods of enzymatic analysis, ed. H. U. Bergmeyer. Academic Press, New York, pp. 1446

De Onis, M., Blössner, M. (2003), The World Health Organization global database on child growth and malnutrition: methodology and applications. Int. J. Epidemiol. 32, 518

Dhahbi, J.M., Mote, P.L., Wingo, J., Tillman, J.B., Walford, R.L., Spindler, S.R. (1999), Calories and aging alter gene expression for gluconeogenic, glycolytic and nitrogen-metabolizing enzymes. Am. J. Physiol. 277, E352

Duff, D.A., Snell, K. (1982), Effects of altered neonatal nutrition on the development of enzymes of lipid and carbohydrate metabolism in the rat. J. Nutr. 112, 1057

Dulloo, A.G., Girardier, L. (1993), Adaptive role of energy expenditure in modulating body fat and protein deposition during catch-up growth after early undernutrition. Am. J. Clin. Nutr. 58, 614

Emery, P.W. (2005), Metabolic changes in malnutrition. Eye 19, 1029
Emmanuel, B., Kennely, J.J. (1984), Effect of propionic acid on ketogenesis in lactating sheep fed restricted rations or deprived of food. J. Dairy Sci. 67, 344

FAO - Food and Agriculture Organization of the United Nations. (2003), Anti-hunger programme: a twintrack approach to hunger reduction: priorities for national and international action. FAO, Rome

Field, J.B. (1989), Exercise and deficient carbohydrate storage and intake as causes of hypoglycemia. Endocrinol. Metab. Clin. North Am. 18, 155

Galende, S., Oliveira Neto, O.C., Santos, L.F., Peicher, M.V., Souza, H.M., Bazotte, R.B. (2009), Glucose administration inhibits the hepatic activation of gluconeogenesis promoted by insulin-induced hypoglycemia. Braz. Arch. Biol. Technol. 52, 849

Gutmann, I., Bergmeyer, H. U. (1974), Determination of urea, indicator reaction with phenol and hypochlorite. In-Methods of enzymatic analysis, ed. H. U. Bergmeyer. Academic Press, New York, pp. 1790

Gutmann, I., Wahlefeld, W.L. (1974), (+)-Lactate determination with lactate dehydrogenase and NAD. In-Methods of enzymatic analysis, ed. H. U. Bergmeyer. Academic Press, New York, pp. 1464

Hagopian, K., Ramsey, J.J., Weindruch, R. (2003), Caloric restriction increases gluconeogenic and transaminase enzyme activities in mouse liver. Exp. Gerontol. 8, 267

Houdijk, M., E., Engelbregt, M.T., Popp-Snijders, C., Delemare Van Der Waal, H.A. (2003), Long-term effects of early postnatal food restriction on growth hormone secretion in rats. J. Parenter. Enteral Nutr. 27, 260

Liu, K.J.M., Jarad, J., Donahue, P.E. (1996), Gluconeogenesis in the livers of diet-restricted rats a $13 \mathrm{C}$ nuclear magnetic resonance study. J. Parent. Enteral Nutr. 20, 178

Mazeti, C.M., Furlan, M.M.D.P. (2008), Crescimento e parâmetros reprodutivos de ratas Wistar sob restrição alimentar desde o nascimento. Acta Sci. Biol. Sci. 30, 197

Oliveira, D.S., Amado, C.A.B., Martini, M.C., SuzukiKemmelmeier, F., Bracht, A. (2007), Glycogen levels and energy status of the liver of fasting rats with diabetes types 1 and 2. Braz. Arch. Biol. Technol. 50, 785

Porter, M.H., Fine J.B., Cutchins, A.G., Bai, Y., Digirolamo, M. (2004), Sexual dimorphism in the response of adipose mass and cellularity to graded caloric restriction. Obes. Res. 12, 131 
Spindler, S.R. (2001), Calorie restriction enhances the expression of key metabolic enzymes associated with protein renewal during aging. Ann. N. Y. Acad. Sci. 928, 296

Valle, A., Catala-Niell, A., Colom, B., Garcia-Palmer, F.J.; Oliver, J., Roca, P. (2005), Sex-related differences in energy balance in response to caloric restriction. Am. J. Physiol. Endocrinol. Metab. 289, E15

Vismara, M.R., Furlan, M.M.D.P. (2007), Parâmetros biométricos como indicadores do grau de desnutrição em ratos sob restrição alimentar desde o nascimento. Arq. Ciências Saúde UNIPAR 11, 3
Waterland, R., Garza, C. (1999), Potential mechanisms of metabolic imprinting that lead to chronic disease. Am. J. Clin. Nutr. 69, 179

Westman, E.C., Feinman, R.D., Mavropoulos, J.C., Vernon, M. C., Volek, J.S., Wortman, J.S., Yancy, W.S., Phinney, S.D. (2007), Low-carbohydrate nutrition and metabolism. Am. J. Clin. Nutr. 86, 276 WHO - World Health Organization. (2005), Global Database on Child Growth and Malnutrition. http://www.who.int/nutgrowthdb/intro_text.htm 